\title{
Cbl upregulates cysH for hydrogen sulfide production in Aeromonas veronii
}

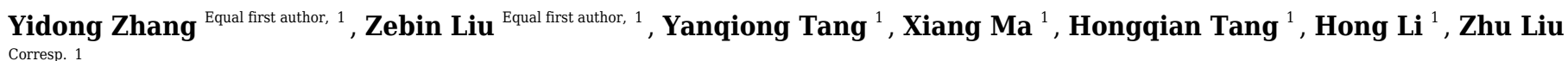 \\ ${ }^{1}$ Hainan University, Haikou, China \\ Corresponding Author: Zhu Liu \\ Email address: zhuliu@hainanu.edu.cn
}

Endogenous hydrogen sulfide $\left(\mathrm{H}_{2} \mathrm{~S}\right)$ is generated in many metabolism pathways, and has been recognized as a second messenger against antibiotics and reactive oxygen species (ROS). In Aeromonas veronii, Small Protein B (SmpB) plays an important role in resisting stress. The absence of $s m p B$ could trigger sulfate assimilation pathway to adapt the nutrient deficiency, of which was mediated by up-regulation of $c b /$ and $c y s$ genes and followed with enhancing $\mathrm{H}_{2} \mathrm{~S}$ production. To figure out the mutual regulations of $\mathrm{cbl}$ and cys genes, a series of experiments were performed. Compared with the wild type, cysH was down-regulated significantly in $c b /$ deletion by qRT-PCR. The fluorescence analysis further manifested that $\mathrm{Cbl}$ had a positive regulatory effect on the promoter of $c y s / H$. Bacterial one-hybrid analysis and electrophoretic mobility shift assay (EMSA) verified that $\mathrm{Cbl}$ bound with the promoter of $c y s J \mathrm{IH}$. Collectively, the tolerance to adversity could be maintained by the production of $\mathrm{H}_{2} \mathrm{~S}$ when $\mathrm{SmpB}$ was malfunctioned, of which the activity of cysJlH promoter was positively regulated by upstream $\mathrm{Cbl}$ protein. The outcomes also suggested the enormous potentials of Aeromonas veronii in environmental adaptability. 


\section{Cbl upregulates cys $\boldsymbol{H}$ for hydrogen sulfide production} 2 in Aeromonas veronii

3

4

5 6

7 8 9

10

11

12

13

14

15

16

17

18

19

20

21

22

23

24

25

26

27

28

29

30

31

32

33

34

35

36
Yidong Zhang ${ }^{1}$, Zebin Liu ${ }^{1}$, Yanqiong Tang ${ }^{1}$, Xiang Ma ${ }^{1}$, Hongqian Tang ${ }^{1}$, Hong $\mathrm{Li}^{1}$, Zhu Liu ${ }^{1}$

${ }^{1}$ Key Laboratory of Tropical Biological Resources of Ministry of Education, School of Life

Sciences, Hainan University, Haikou, Hainan, China

Corresponding Author:

Zhu Liu ${ }^{1}$

Hainan University, Haikou, Hainan, 570228, China

Email address: zhuliu@hainanu.edu.cn 


\section{Abstract}

38 Endogenous hydrogen sulfide $\left(\mathrm{H}_{2} \mathrm{~S}\right)$ is generated in many metabolism pathways, and has been

39

40

41

42

43

44

45

46

47

48

49

50

51

52

53

54

55

56

57

58

59

60

61

62

63

64

65

66

67

68

69

70

71

72

73

74

75

76

recognized as a second messenger against antibiotics and reactive oxygen species (ROS). In Aeromonas veronii, Small Protein B $(\mathrm{SmpB})$ plays an important role in resisting stress. The absence of $\operatorname{smp} B$ could trigger sulfate assimilation pathway to adapt the nutrient deficiency, of which was mediated by up-regulation of $c b l$ and $c y s$ genes and followed with enhancing $\mathrm{H}_{2} \mathrm{~S}$ production. To figure out the mutual regulations of $c b l$ and $c y s$ genes, a series of experiments were performed. Compared with the wild type, $c y s H$ was down-regulated significantly in $c b l$ deletion by qRT-PCR. The fluorescence analysis further manifested that $\mathrm{Cbl}$ had a positive regulatory effect on the promoter of cysJIH. Bacterial one-hybrid analysis and electrophoretic mobility shift assay (EMSA) verified that $\mathrm{Cbl}$ bound with the promoter of cysJIH. Collectively, the tolerance to adversity could be maintained by the production of $\mathrm{H}_{2} \mathrm{~S}$ when $\mathrm{SmpB}$ was malfunctioned, of which the activity of cysJIH promoter was positively regulated by upstream $\mathrm{Cbl}$ protein. The outcomes also suggested the enormous potentials of Aeromonas veronii in environmental adaptability.

\section{Introduction}

Aeromonas veronii is widely present in fresh water, sewage, soil and even sea water (HickmanBrenner et al., 1987), which endows with strong resistance to multiple antibiotics (Liu et al., 2018). Small Protein B (SmpB) acts as a small RNA binding protein in the trans-translation system to help transfer messenger RNA (tmRNA) to rescue the retained ribosomes in bacteria (Wali Karzai, Susskind \& Sauer, 1999). Also, SmpB performs many significant functions in biological regulation. For example, the expression of ribonuclease R (RNase R), an exonuclease molecule that recognizes and degrades RNA, depends on SmpB in Streptococcus pneumoniae (Moreira et al., 2012). SmpB protein promotes the binding and degradation of RNase R by HslUV and Lon in Escherichia coli (Liang \& Deutscher, 2012). Moreover, SmpB has similar effects with the known RNA chaperone proteins such as CrsA and Hfq. The loss of SmpB affects $4 \%$ transcription changes of genes in salmonella, of which involves in biological processes, including invasion, bacterial movement, central metabolism, lipopolysaccharide (LPS) biosynthesis, two-component regulatory system and fatty acid metabolism (Sittka et al., 2007; Ansong et al., 2009). In all, SmpB is essential for intra-macrophage proliferation and the strong adaptability to oxidative stress in Salmonella (Ansong et al., 2009). However, the mechanism of SmpB increasing the adaptability to stress is vague. To survive in oxidative damage, the bacteria evolve the enzymatic antioxidants such as superoxide dismutase (SOD) to tolerate peroxide anion radicals (He et al., 2017). Furthermore, bacterial hydrogen sulfide $\left(\mathrm{H}_{2} \mathrm{~S}\right)$ could increase SOD activity and maintain redox balance in vivo (Shukla et al., 2017). $\mathrm{H}_{2} \mathrm{~S}$ is a gaseous molecule with unpleasant smell which at high concentrations is toxic to most living organisms/live cells etc. (Lindenmann et al., 2010). However, the low concentration of $\mathrm{H}_{2} \mathrm{~S}$ participates in bacterial defense against reactive oxygen species (ROS) and antibiotics-induced oxidative damage (Lindenmann et al., 2010). Since $\mathrm{H}_{2} \mathrm{~S}$ is water-soluble, a considerable amount of $\mathrm{H}_{2} \mathrm{~S}$ exists in the form of $\mathrm{HS}^{-1}$. It is hardly distinguished whether $\mathrm{H}_{2} \mathrm{~S}$ or $\mathrm{HS}^{-1}$ that contributes to the biological

Peer] reviewing PDF | (2021:03:59116:2:0:NEW 21 Jul 2021) 
77

78

79

80

81

82

83

84

85

86

87

88

89

90

91

92

93

94

95

96

97

98

99

100

101

102

103

104

105

106

107

108

109

110

111

112

113

114

115

116

activity. Therefore, $\mathrm{H}_{2} \mathrm{~S}$ mentioned in biologically relevant article virtually contains both species in case of confusion (Powell, Dillon \& Matson, 2018). One of the basic $\mathrm{H}_{2} \mathrm{~S}$ synthesis includes sulfate assimilation pathway, which is catalyzed by cysNDC and cysJIH (Shatalin et al., 2011; Kimura, 2014; Wu et al., 2015). In Salmonella typhimurium, the expression of cysJIH is regulated by $\mathrm{CysB}$ which has $41 \%$ amino acid sequence homology with $\mathrm{Cbl}$ (Iwanicka-Nowicka et al., 2007; Álvarez et al., 2015), there is little evidence regarding the role of $\mathrm{Cbl}$ in regulating cysJIH in Aeromonas species. Both CysB and Cbl are LysR-type transcriptional activator. In sulfur metabolism, Cbl acts as a sensor of the intracellular sulphate level, and activates tau and ssu promoter in vivo and in vitro (Van Der Ploeg et al., 1999; Van Der Ploeg, Eichhorn \& Leisinger, 2001; Bykowski et al., 2002). In addition, Cbl activates sulfate starvation-induced genes under sulfate starvation (Van Der Ploeg et al., 1999). Taking together, there may be a potential connection between $\mathrm{Cbl}$ and cys genes in sulfate assimilation pathway.

In Aeromonas veronii, both $\mathrm{SmpB}$ and $\mathrm{H}_{2} \mathrm{~S}$ play important roles in adverse stress. The absence of $\mathrm{SmpB}$ induced the generation of $\mathrm{H}_{2} \mathrm{~S}$ helping to survive. The transcriptomic analysis revealed that both $c b l$ and $c y s$ genes were up-regulated in SmpB deletion strain. To clarify the regulatory relationship between $c b l$ and $c y s$ genes in sulfate assimilation pathway, Real-time PCR experiment and fluorescence analysis were performed, showing that $\mathrm{Cbl}$ positively regulated cys $H$ gene. Furthermore, bacterial one-hybrid system and EMSA verified that Cbl regulated $c y s H$ by binding to the promoter of cysJIH. In brief, Cbl bound and activated cysJIH promoter directly to increase $\mathrm{H}_{2} \mathrm{~S}$ production, remedying the survival ability after $\operatorname{smpB}$ deficiency. Our study elucidated the strong vitality and adaptability of Aeromonas veroniiin adverse stress. We also uncovered a novel model of $\mathrm{H}_{2} \mathrm{~S}$ biosynthetic mechanism that may be contributed to stressful survival and recalcitrance of bacterial infections.

\section{Materials \& Methods}

\section{Bacterial strains, plasmids and culture conditions}

The bacterial strains and plasmids used in this study were shown in supplemental Table S1. The smpB deletion strain of Aeromonas veronii C4 was constructed previously (Liu et al., 2015). The derivative Aeromonas veronii C4 strains were grown in LB/M9 medium supplemented with 50 $\mathrm{mg} / \mathrm{mL}$ ampicillin at $30^{\circ} \mathrm{C}$, and $E$. coli strains were grown in LB medium supplemented with 50 $\mathrm{mg} / \mathrm{mL}$ kanamycin and $25 \mathrm{mg} / \mathrm{mL}$ chloramphenicol at $37^{\circ} \mathrm{C}$. And all plasmids were sequenced for verification. LB medium contained $10 \%$ tryptone, $5 \%$ yeast extract and $10 \% \mathrm{NaCl}$. M9 medium contained $20 \% 5 \times \mathrm{M} 9$ salts, $0.2 \% 1 \mathrm{M} \mathrm{MgSO}_{4}, 0.01 \% 1 \mathrm{M} \mathrm{CaCl}_{2}$ and $0.4 \%$ Glucose, of which $5 \times \mathrm{M} 9$ salts included $6.4 \% \mathrm{Na}_{2} \mathrm{PO}_{4} \cdot 7 \mathrm{H}_{2} \mathrm{O}, 1.5 \% \mathrm{KH}_{2} \mathrm{PO}_{4}, 0.25 \% \mathrm{NaCl}$ and $0.5 \% \mathrm{NH}_{4} \mathrm{Cl}$.

\section{Complemented strain construction}

The DNA fragment including both $c b l$ gene and its promoter was amplified by PCR (Wang et al., 2019). PCR reaction was performed as follow: $98^{\circ} \mathrm{C}$ for $2 \mathrm{~min}$, stepped by $98^{\circ} \mathrm{C}$ for $30 \mathrm{sec}, 55^{\circ} \mathrm{C}$ for $30 \mathrm{sec}$ and $72^{\circ} \mathrm{C}$ for $1 \mathrm{~kb} / \mathrm{min}$ in 30 cycles. The purified PCR product wasinserted into pBBR plasmid for creating pBBR-Cbl expression plasmid. The $c b l$ deletion strains were complemented by the conjugation of recipient WM3064 strains carrying pBBR-Cbl 


\section{3. $\mathbf{H}_{2} \mathrm{~S}$ Detection}

118 The $\mathrm{Pb}(\mathrm{Ac})_{2}$ detection (Shatalin et al., 2011) method and WSP5 fluorescent $\mathrm{H}_{2} \mathrm{~S}$ probe (Peng et 119 al., 2014) were performed for monitoring $\mathrm{H}_{2} \mathrm{~S}$ production in gas and liquid phases, respectively. 120 Bacteria were grown in $\mathrm{M} 9$ at $30^{\circ} \mathrm{C}$ for $48 \mathrm{~h}$ with soaked $\mathrm{Pb}(\mathrm{Ac})_{2}$ paper strips hanging from the 121 mouth of the conical bottle, and $5 \mathrm{mg} / \mathrm{L} \mathrm{Na}_{2} \mathrm{SO}_{3}$ was added as a source of sulfur. $\mathrm{Pb}(\mathrm{Ac})_{2}$-soaked 122 paper strips showed a $\mathrm{PbS}$ brown stain as a result of the reaction with $\mathrm{H}_{2} \mathrm{~S}$. The color length of $1231 \mathrm{~mm}$ represented $12 \mu \mathrm{g} / \mathrm{L}$ of $\mathrm{H}_{2} \mathrm{~S}$ production. After $10 \mu \mathrm{M}$ WSP5 was added to liquid bacterial 124 culture, the samples were incubated at $37^{\circ} \mathrm{C}$ for $30 \mathrm{~min}$ and then washed in PBS buffer to remove 125 excess probe. Synergy H1 (BioTek) was used to take fluorescent readings at excitation $500 \mathrm{~nm}$ 126 and emission $533 \mathrm{~nm}$. Each reaction was performed at least in triplicate.

127

128

129

130

131

132

133

134

135

136

137

138

139

140

141

142

143

144

145

146

147

148

149

150

151

152

153

154

155

156

\section{RNA Extraction and qRT-PCR}

The qPCR reaction was conducted with ABI Prism ${ }^{\circledR} 7300$ (ABI, New York, NY, USA) for fluorescent detection utilizing SYBRR ${ }^{\circledR}$ Green real time PCR Master Mix (Toyonbo, Shanghai, China). The cDNA was synthesized by RNA reverse transcription reaction and was used as the template for real-time PCR. The primers used to monitor expression of the objective genes were summarized in supplemental Table S2. Each reaction was performed at least in triplicate, and wild type (WT) was chosen as the control. And the data was analyzed by the comparative CT method (Schmittgen \& Livak, 2008).

\section{Fluorescence analysis}

The promoter of $c y s J I H$ was fused with eGFP and inserted into pUC19 plasmid. The $c b l$ gene was cloned into pTRG plasmid simultaneously. Both the above plasmids were co-transformed into E. coli Reporter strain. In the meanwhile, the recombinant pUC19 plasmid and the empty pTRG plasmid were co-transformed as the negative control. After bacteria were grown in LB at $37^{\circ} \mathrm{C}$, the total amount of $1 \times 10^{8}$ cells were harvested in $1.5 \mathrm{~mL}$ eppendorf tube at interval time.

\section{The samples were washed with PBS twice, and placed on Synergy H1 (Biotek) for the} fluorescent readings at excitation $425 \mathrm{~nm}$ and emission $525 \mathrm{~nm}$. Each reaction was performed at least in triplicate.

\section{Bacterial one-hybrid analysis}

To identify whether the transcription factor $\mathrm{Cbl}$ interacted with the promoter of cys $I H, \mathrm{Cbl}$ was inserted into pTRG, and the promoter of cys JIH was ligated with $\mathrm{pBXcmT}$, following with both the recombinant plasmids were cotransformed into E. coli Reporter strain. The transformants were placed on a selective NM medium plate containing $5 \mathrm{mM}$ 3-amino-1, 2, 4-triazole (3-AT) and $12.5 \mathrm{mg} / \mathrm{mL}$ streptomycin for incubation at $37^{\circ} \mathrm{C}$ for $48 \mathrm{~h}$. The pTRG and $\mathrm{pBXcmT}$ plasmids were co-transformed as the negative control, and pTRG-GAL and pBT-LGF2 were cotransformed as the positive control.

\section{Protein expression and purification}

The $c b l$ gene was inserted into pET28a plasmid and transformed into E. coli BL21 strain. The expression and purification were performed according to previous procedure (Bykowski et al., 2002). Cbl protein was purified from E. coli BL21 harboring the pET28a-Cbl plasmid. The recombinant bacteria were grown in $\mathrm{LB}$ at $37^{\circ} \mathrm{C}$ until the logarithmic phase, followed by the 
157

158

159

160

161

162

163

164

165

166

167

168

169

170

171

172

173

174

175

176

177

178

179

180

181

182

183

184

185

186

187

188

189

190

191

192

193

194

195

addition of $0.1 \mathrm{mM}$ IPTG to induce protein expression at $15^{\circ} \mathrm{C}$ for $14 \mathrm{~h}$. And the cells were harvested in Tris- $\mathrm{HCl}$ and lysed by sonication. The supernatant was collected after centrifugation and loaded onto a Ni-NTA column. The sample was eluted prior to the dialysis, and SDS-PAGE was used to assess protein purity.

\section{Electrophoretic mobility shift assay (EMSA)}

Double stranded DNA probes were radiolabeled with Fluorophore 6-carboxy-fluorescein (FAM) and purified by FastPure Gel DNA Extraction Mini Kit (Vazyme). For the EMSA, DNA probe was incubated with $\mathrm{Cbl}$ protein samples in reaction buffer $(10 \mathrm{mM}$ Tris- $\mathrm{HCl}, 1 \mathrm{mM} \mathrm{MgCl}, 1$ $\mathrm{mM}$ DTT, $40 \mathrm{mM} \mathrm{KCl}, 0.1 \mathrm{mg} / \mathrm{mL} \mathrm{BSA}, 5 \%(\mathrm{w} / \mathrm{v})$ glycerol) at $37^{\circ} \mathrm{C}$ for $30 \mathrm{~min}$. After the samples were separated using a 6\% native acrylamide gel (Zhang et al., 2020), the gel was then exposed to a phosphorscreen and visualized on Typhoon FLA 9500.

\section{Transcriptome analysis}

To perform the whole-transcriptome analysis, the wild type and $\operatorname{smpB}$ deletion of Aeromonas veronii $\mathrm{C} 4$ were grown in $\mathrm{M} 9$ at $30^{\circ} \mathrm{C}$ for $20 \mathrm{~h}$, and $2 \mathrm{OD}_{600}$ of cells were collected. Illumina HiSeq-X ten based on the service of RNA-Seq Quantification library at BGI-Shenzhen (China) was used to obtain the transcriptome sequencings. And the RNA-seq raw data was assembled and analyzed by comparing with the translational region of the annotated DNA sequence in reference genome (GCA_001593245.1) using HISAT (Kim, Langmead \& Salzberg, 2015). The DESeq. 2 package in $\mathrm{R}$ was used for the estimation of fold changes and other analysis (Love, Huber \& Anders, 2014).

\section{Statistical analyses}

Statistical significance was determined by $t$ test (two-tailed distribution with two-sample, equal variance) when directly comparing two conditions or a one-way analysis of variance (ANOVA) and Tukey post-test by pairwise comparisons.

\section{Results}

\section{Transcriptomic analysis}

Based on the transcriptomic analysis, the deletion of SmpB mainly caused the changes in 20 biological pathways, including two-component system, sulfur metabolism, plant pathogenic bacteria interaction, and phenylalanine metabolism. Sulfur metabolism was the most influential on metabolic pathways (Fig.1A).

In Aeromonas veronii $\mathrm{C} 4, \mathrm{H}_{2} \mathrm{~S}$ synthesis pathway included the sulfate assimilation pathway, the organic pathway, and the 3-MST pathway. But compared with others, Aeromonas veronii $\mathrm{C} 4$ lacked cystathionine $\beta$-synthase (CBS) in the transsulfuration pathway and cysteine aminotranferase (CAT) in the 3MST pathway. The deletion of SmpB mainly up-regulated the transcription levels of $c y s N, c y s D, c y s C, c y s H, c y s J, c y s I$ and $c b l$ (Fig.1B). And these genes were mainly involved in sulfate assimilation pathway (Fig.1C). The transcription of cysB did not change. Therefore, we speculated that $\mathrm{SmpB}$ deficiency was able to increase $\mathrm{H}_{2} \mathrm{~S}$ synthesis. 
196

197

198

199

200

201

202

203

204

205

206

207

208

209

210

211

212

213

214

215

216

217

218

219

220

221

222

223

224

225

226

227

228

229

230

231

232

233

234

235

\section{The production of $\mathrm{H}_{2} \mathrm{~S}$ was increased in the absence of $\mathrm{SmpB}$ under nutritionally} deficient conditions

To figure out how sulfur metabolism was affected by $\mathrm{SmpB}$ deficiency, $\mathrm{H}_{2} \mathrm{~S}$ production was measured in rich and deficient nutrition conditions by $\mathrm{Pb}(\mathrm{Ac})_{2}$ detection test. There is no difference between wild type (WT) and $\operatorname{smp} B$ deletion in a rich medium (LB medium) (Fig.2A). Under the condition of nutritional deficiency (M9 medium), the $\operatorname{smp} B$ deletion produced less amount of $\mathrm{H}_{2} \mathrm{~S}$ in the early stage of growth, but it enhanced to synthesize $\mathrm{H}_{2} \mathrm{~S}$ in the stationary stage (Fig.2B). The final $\mathrm{H}_{2} \mathrm{~S}$ yield of $s m p B$ deletion was significantly higher than that of WT. This suggested that the production of $\mathrm{H}_{2} \mathrm{~S}$ was increased in the absence of SmpB during auxotrophic conditions, especially predominant during the stationary phase of bacterial growth.

\section{Cbl affects the generation of $\mathrm{H}_{2} \mathrm{~S}$}

Using both the classic $\mathrm{Pb}(\mathrm{Ac})_{2}$ detection test and a fluorescent-based probe WSP5 (Zhang et al., 2020), we confirmed that, the production of $\mathrm{H}_{2} \mathrm{~S}$ in $c b l$ deletion strain was significantly lower than that of WT in M9 medium (Fig.3A; Fig.3B). And the difference was offset when Cbl protein was complemented (Fig.3A; Fig.3B). All the results were consistent with the transcriptome data, implying that $\mathrm{Cbl}$ had a positive regulatory effect on the synthesis of $\mathrm{H}_{2} \mathrm{~S}$ under nutritional deficiency.

\section{Cbl promotes the transcription of $c y s H$}

The amino acid sequence of $c b l$ gene was highly homologous to the $c y s B$ family, and CysB was proved to binding with the promoter of sulfur reductase (CysJIH) as a transcription factor for regulation. Therefore, it was speculated that $c b l$ regulated the transcription of genes such as cys $H$, cys $J$ and $c y s I$. The relative expression of $c y s H$ decreased significantly compared WT with cbl deletion by RT-qPCR, while those of cysI, cys $J$ revealed no differences (Fig.3C). Furthermore, the fusion of the promoter cysJIH (PcysJIH) and eGFP was constructed as the indicator plasmid for the fluorescent measurement. When co-expressed with $\mathrm{Cbl}$, the fluorescence value was extremely significantly higher than that of the strain containing only PcysJIH (Fig.3D). Collectively, Cbl had a positive regulation on PcysJIH.

\section{Cbl regulates downstream $c y s H$ by binding to the PcysJIH}

To confirm whether $\mathrm{Cbl}$ bound to PcysJIH, the PcysJIH promoter sequence and Cbl coding sequence were cloned into $\mathrm{pBXcmT}$ and pTGR plasmids respectively, and then co-transformed into E. coli XL 1-Blue MRF' reporter strain for bacterial one-hybrid experiment. Only the coexpressed strain and the positive control grew on the minimum medium supplemented with $6 \mathrm{mM}$ 3-AT and streptomycin (Fig.4A), suggesting that the strong interaction between PcysJIH and Cbl.

Next PcysJIH was labelled with Fluorophore 6-carboxy-fluorescein (6-FAM) for electrophoretic mobility shift assay (EMSA). The Cbl protein reduced the mobility of the 6-FAM-PcysJIH DNA probe corresponding to the increased Cbl concentration with the enhanced Cbl-DNA complex (Fig.4B). So Cbl protein was able to bind with $\mathrm{P} c y s J I H$ following with the regulation of $\mathrm{H}_{2} \mathrm{~S}$ production.

\section{Determination of the binding region of PcysJIH with $\mathrm{Cbl}$ protein}


236 To confirm the binding region of PcysJIH with Cbl protein, we truncated the full length of $237 \mathrm{P}$ cysJIH to 150bp and 50bp upstream of transcriptional initiation which were named as $238 \mathrm{P}$ cys $J I H^{150}$ and $\mathrm{P} c y s J I H^{50}$. Pcys $J I H^{150}$ was able to form a complex with Cbl protein, while $239 \mathrm{P}$ cys $J I H^{50}$ lost the binding ability (Fig.4C). The result suggested that the regions between 50bp 240 and 150bp upstream of transcriptional initiation in PcysJIH were responsible for the binding of

241 Cbl.

\section{Discussion}

$243 \mathrm{SmpB}$ protein is involved in the regulation of multiple biological processes such as protein 244 invasion, bacterial movement, central metabolism, lipopolysaccharide biosynthesis, two245 component system, fatty acid metabolism, high temperature tolerance, cell cycle, and stress 246 response (Shin \& Price, 2007; Ansong et al., 2009; Barends et al., 2010). And the destruction of 247 SmpB reduces the tolerance and adaptability of bacteria (Ansong et al., 2009).

248 Bacterial $\mathrm{H}_{2} \mathrm{~S}$ has been proved toresist oxidative stress by reacting with reactive oxygen species 249 (ROS), $\mathrm{H}_{2} \mathrm{O}_{2}$, etc. or stimulate catalase and superoxide dismutase to scavenging free radicals 250 (Kimura, 2014; Mironov et al., 2017). Besides, the oxidative stress effect of $\mathrm{H}_{2} \mathrm{~S}$ is also related to

251

252

253

254

255

256

257

258

259

260

261

262

263

264

265

266

267

268

269

270

271

272

273

274

the defense of bacteria against antibiotics, because many antibiotics also trigger the production of ROS when they function as the targeted inhibition (Kohanski et al., 2007). So, the effect of $\mathrm{H}_{2} \mathrm{~S}$ in scavenging ROS can make it more resistant to antibiotics.

In our study, the $\operatorname{smp} B$ deletion of Aeromonas veronii $\mathrm{C} 4$ was significantly higher in $\mathrm{H}_{2} \mathrm{~S}$ production than wild type under M9 culture condition (Fig.2B), implying that SmpB deficiency enhanced the $\mathrm{H}_{2} \mathrm{~S}$ generation. Indeed, $\operatorname{smp} B$ deletion up-regulated multiple genes in sulfate assimilation pathway, including $c y s N, c y s D, c y s C, c y s H$, cysJ, cysI and $c b l$ (Fig.1B; Fig.1C). In Salmonella Typhimurium, the promoter of cysJIH (PcysJIH) is regulated by CysB (Álvarez et al., 2015), which is homologous with $\mathrm{Cbl}$ (Kertesz, 2000). Therefore, we presumed that $\mathrm{Cbl}$ was responsible for the regulation of cys $\mathrm{H}, \mathrm{cys} J$ and cysI in Aeromonas veronii $\mathrm{C} 4$. $\mathrm{Cbl}$ bound to PcysJIH and positively regulated the transcription of $c y s H$ (Fig.3D; Fig.4A; Fig.4B; Fig.4C). Previously $\operatorname{smp} B$ deletion exhibits more tolerance to aminoglycosides antibiotic and oxidative stress under M9 culture (Fig.2C) (Liu et al., 2018; Wang et al., 2019). In summary, we proposed that $\mathrm{Cbl-regulated} \mathrm{H}_{2} \mathrm{~S}$ generation compensated for the resistance and survival of SmpB damage under nutrient deficiencies, contributing to the adaptation and evolution of Aeromonas veronii against extreme environment.

\section{Conclusions}

This study provided the first demonstration for the regulation between $\mathrm{Cbl}$ and cysJIH, and innovatively proposed the mechanism of Cbl-mediated $\mathrm{H}_{2} \mathrm{~S}$ synthesis. Previously the strain of smpB deletion was observed to survive better than WT under the appropriate concentration of $\mathrm{H}_{2} \mathrm{O}_{2}$. In view of the function of $\mathrm{H}_{2} \mathrm{~S}$ in oxidative resistance, we speculated that the accumulation of $\mathrm{H}_{2} \mathrm{~S}$ increased the tolerance of oxidative resistance in SmpB deficiency. The results expanded the function of $\mathrm{Cbl}$ in pathogenic bacteria, and systematically explained the dynamic role of $\mathrm{H}_{2} \mathrm{~S}$ in protecting bacteria from oxidative stress. These findings provide potential drug targets for

Peerj reviewing PDF | (2021:03:59116:2:0:NEW 21 Jul 2021) 
275 aquatic diseases, offers theoretical basis for better understanding of bacterial pathogens

276

277

278

279

280

281

282

283

284

285

286

287

288

289

290

291

292

293

294

295

296

297

298

299

300

301

302

303

304

305

306

307

308

309

310

311

312

313

314

315

316

resistance to environmental stress and supplies new ideas for clinical prevention and control of bacterial pathogens.

\section{Acknowledgements}

This work was supported by the grants from National Natural Science Foundation of China Nos. 31772887 (to Z.L.)

\section{References}

Álvarez R, Neumann G, Frávega J, Díaz F, Tejías C, Collao B, Fuentes JA, Paredes-Sabja D, Calderón IL, Gil F. 2015. CysB-dependent upregulation of the Salmonella Typhimurium cysJIH operon in response to antimicrobial compounds that induce oxidative stress. Biochemical and Biophysical Research Communications 458:46-51. DOI: 10.1016/j.bbrc.2015.01.058.

Ansong C, Yoon H, Porwollik S, Mottaz-Brewer H, Petritis BO, Jaitly N, Adkins JN, McClelland M, Heffron F, Smith RD. 2009. Global systems-level analysis of Hfq and SmpB deletion mutants in Salmonella: Implications for virulence and global protein translation. PLoS ONE 4. DOI: 10.1371/journal.pone.0004809.

Barends S, Zehl M, Bialek S, De Waal E, Traag BA, Willemse J, Jensen ON, Vijgenboom E, Van Wezel GP. 2010. Transfer-messenger RNA controls the translation of cell-cycle and stress proteins in Streptomyces. EMBO Reports 11:119-125. DOI: 10.1038/embor.2009.255.

Bykowski T, Van Der Ploeg JR, Iwanicka-Nowicka R, Hryniewicz MM. 2002. The switch from inorganic to organic sulphur assimilation in Escherichia coli: Adenosine 5'-phosphosulphate (APS) as a signalling molecule for sulphate excess. Molecular Microbiology. DOI: 10.1046/j.1365-2958.2002.02846.x.

He L, He T, Farrar S, Ji L, Liu T, Ma X. 2017. Antioxidants Maintain Cellular Redox Homeostasis by Elimination of Reactive Oxygen Species. Cellular Physiology and Biochemistry 44. DOI: 10.1159/000485089.

Hickman-Brenner FW, MacDonald KL, Steigerwalt AG, Fanning GR, Farmer JJ. 1987. Aeromonas veronii, a new ornithine decarboxylase-positive species that may cause diarrhea. Journal of Clinical Microbiology 25:900-906. DOI: 10.1128/jcm.25.5.900-906.1987.

Iwanicka-Nowicka R, Zielak A, Cook AM, Thomas MS, Hryniewicz MM. 2007. Regulation of sulfur assimilation pathways in Burkholderia cenocepacia: Identification of transcription factors CysB and SsuR and their role in control of target genes. Journal of Bacteriology 189:1675-1688. DOI: 10.1128/JB.00592-06.

Kertesz MA. 2000. Riding the sulfur cycle - Metabolism of sulfonates and sulfate esters in Gram-negative bacteria. FEMS Microbiology Reviews 24:135-175. DOI: 10.1016/S01686445(99)00033-9.

Kim D, Langmead B, Salzberg SL. 2015. HISAT: A fast spliced aligner with low memory requirements. Nature Methods 12. DOI: 10.1038/nmeth.3317.

Kimura H. 2014. Production and physiological effects of hydrogen sulfide. Antioxidants and Redox Signaling 20:783-793. DOI: 10.1089/ars.2013.5309. 
317 Kohanski MA, Dwyer DJ, Hayete B, Lawrence CA, Collins JJ. 2007. A Common Mechanism of

318

319

320

321

322

323

324

325

326

327

328

329

330

331

332

333

334

335

336

337

338

339

340

341

342

343

344

345

346

347

348

349

350

351

352

353

354

355

356

357

358

359

360

361 10.1016/j.cell.2007.06.049.

Liang W, Deutscher MP. 2012. Transfer-messenger RNA-SmpB protein regulates ribonuclease

$\mathrm{R}$ turnover by promoting binding of HslUV and lon proteases. Journal of Biological Chemistry 287:33472-33479. DOI: 10.1074/jbc.M112.375287.

Lindenmann J, Matzi V, Neuboeck N, Ratzenhofer-Komenda B, Maier A, Smolle-Juettner FM. 2010. Severe hydrogen sulphide poisoning treated with 4-dimethylaminophenol and hyperbaric oxygen. Diving and Hyperbaric Medicine 40:213-217.

Liu Z, Hu K, Tang Y, Li H, Tang H, Hu X, Ma X, Liu Z. 2018. SmpB down-regulates protonmotive force for the persister tolerance to aminoglycosides in Aeromonas veronii.

Biochemical and Biophysical Research Communications 507:407-413. DOI: 10.1016/j.bbrc.2018.11.052.

Liu Z, Liu P, Liu S, Song H, Tang H, Hu X. 2015. Small protein B upregulates sensor kinase bvgS expression in Aeromonas veronii. Frontiers in Microbiology 6:1-10. DOI: 10.3389/fmicb.2015.00579.

Love MI, Huber W, Anders S. 2014. Moderated estimation of fold change and dispersion for RNA-seq data with DESeq2. Genome Biology 15. DOI: 10.1186/s13059-014-0550-8.

Mironov A, Seregina T, Nagornykh M, Luhachack LG, Korolkova N, Lopes LE, Kotova V, Zavilgelsky G, Shakulov R, Shatalin K, Nudler E. 2017. Mechanism of H2S-mediated protection against oxidative stress in Escherichia coli. Proceedings of the National Academy of Sciences of the United States of America 114:6022-6027. DOI: 10.1073/pnas.1703576114.

Moreira RN, Domingues S, Viegas SC, Amblar M, Arraiano CM. 2012. Synergies between RNA degradation and trans-translation in Streptococcus pneumoniae: Cross regulation and cotranscription of RNase R and SmpB. BMC Microbiology 12. DOI: 10.1186/1471-2180-12268.

Peng B, Chen W, Liu C, Rosser EW, Pacheco A, Zhao Y, Aguilar HC, Xian M. 2014. Fluorescent probes based on nucleophilic substitution-cyclization for hydrogen sulfide detection and bioimaging. Chemistry - A European Journal 20:1010-1016. DOI: 10.1002/chem.201303757.

Van Der Ploeg JR, Eichhorn E, Leisinger T. 2001. Sulfonate-sulfur metabolism and its regulation in Escherichia coli. Archives of Microbiology 176:1-8. DOI: $10.1007 / \mathrm{s} 002030100298$.

Van Der Ploeg JR, Iwanicka-Nowicka R, Bykowski T, Hryniewicz MM, Leisinger T. 1999. The Escherichia coli ssuEADCB gene cluster is required for the utilization of sulfur from aliphatic sulfonates and is regulated by the transcriptional activator Cb1. Journal of Biological Chemistry 274:29358-29365. DOI: 10.1074/jbc.274.41.29358.

Powell CR, Dillon KM, Matson JB. 2018. A review of hydrogen sulfide (H2S) donors: Chemistry and potential therapeutic applications. Biochemical Pharmacology 149. DOI: 10.1016/j.bcp.2017.11.014.

Schmittgen TD, Livak KJ. 2008. Analyzing real-time PCR data by the comparative CT method. Nature Protocols 3:1101-1108. DOI: 10.1038/nprot.2008.73.

Shatalin K, Shatalina E, Mironov A, Nudler E. 2011. H2S: A universal defense against antibiotics in bacteria. Science 334:986-990. DOI: 10.1126/science.1209855. 
362

363

364

365

366

367

368

369

370

371

372

373

374

375

376

377

378

379

380

381

382

383

384

385

Shin JH, Price CW. 2007. The SsrA-SmpB ribosome rescue system is important for growth of Bacillus subtilis at low and high temperatures. Journal of Bacteriology 189:3729-3737. DOI: 10.1128/JB.00062-07.

Shukla P, Khodade VS, Sharathchandra M, Chauhan P, Mishra S, Siddaramappa S, Pradeep BE, Singh A, Chakrapani H. 2017. "on demand" redox buffering by H2S contributes to antibiotic resistance revealed by a bacteria-specific H2S donor. Chemical Science 8. DOI: $10.1039 / \mathrm{c} 7 \mathrm{sc} 00873 \mathrm{~b}$.

Sittka A, Pfeiffer V, Tedin K, Vogel J. 2007. The RNA chaperone Hfq is essential for the virulence of Salmonella typhimurium. Molecular Microbiology 63:193-217. DOI: 10.1111/j.1365-2958.2006.05489.x.

Wali Karzai A, Susskind MM, Sauer RT. 1999. SmpB, a unique RNA-binding protein essential for the peptide-tagging activity of SsrA (tmRNA). EMBO Journal. DOI: 10.1093/emboj/18.13.3793.

Wang D, Li H, Ma X, Tang Y, Tang H, Hu X, Liu Z. 2019. Small RNA AvrA regulates IscR to increase the stress tolerances in SmpB deficiency of aeromonas veronii. Frontiers in Cellular and Infection Microbiology 9:1-12. DOI: 10.3389/fcimb.2019.00142.

Wu G, Li N, Mao Y, Zhou G, Gao H. 2015. Endogenous generation of hydrogen sulfide and its regulation in Shewanella oneidensis. Frontiers in Microbiology 6. DOI: 10.3389/fmicb.2015.00374.

Zhang F, Li B, Dong H, Chen M, Yao S, Li J, Zhang H, Liu X, Wang H, Song N, Zhang K, Du N, Xu S, Gu L. 2020. YdiV regulates Escherichia coli ferric uptake by manipulating the DNA-binding ability of Fur in a SlyD-dependent manner. Nucleic acids research 48:95719588. DOI: $10.1093 /$ nar/gkaa696. 
Figure 1

Transcriptomic analysis between wild type (WT) and smpB knockout.

(A) The KEGG pathways for the different metabolites between WT and the smpB deletion $(\triangle s m p B)$. (B) The relative expression of the correlated $\mathrm{H}_{2} \mathrm{~S}$ synthesis genes in WT and $\Delta s m p B$ cells. Values represented means $\pm S D(n=3)$. ${ }^{* * *} p<0.001$ was determined by one-way ANOVA and Tukey post-test. (C) The deletion of $s m p B$ enhanced the expression of genes in sulfate assimilation pathway.

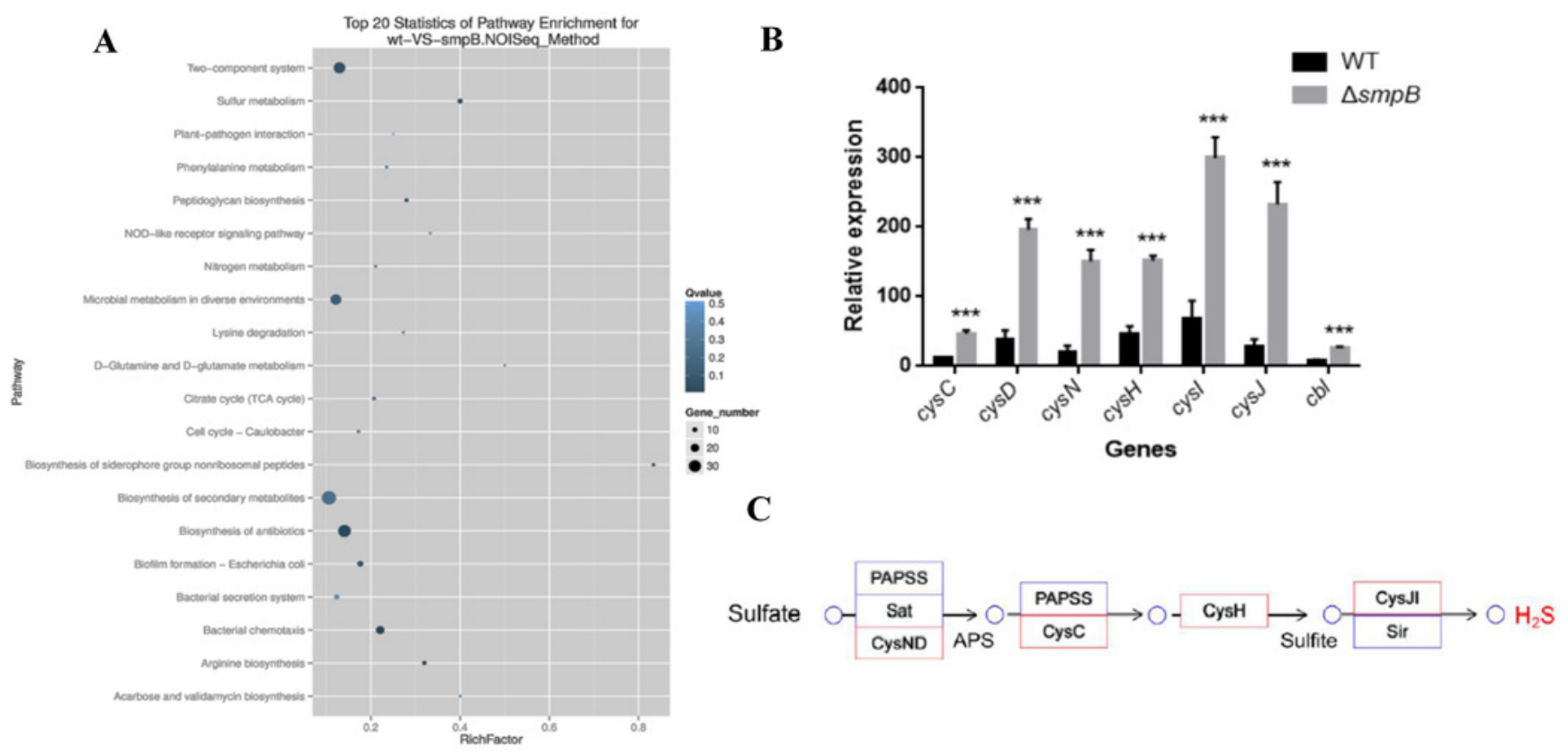


Figure 2

The production of $\mathrm{H}_{2} \mathrm{~S}$ were increased in the absence of $\mathrm{SmpB}$ under nutritionally deficient conditions

(A) $\mathrm{H}_{2} \mathrm{~S}$ production was measured by $\mathrm{Pb}(\mathrm{Ac})_{2}$-soaked paper strips in LB medium supplemented with $5 \mathrm{mg} / \mathrm{L} \mathrm{Na}_{2} \mathrm{SO}_{3}$. No significant differences existed between WT and $\Delta s m p B$ strains. (B) $\mathrm{H}_{2} \mathrm{~S}$ production was measured by $\mathrm{Pb}(\mathrm{Ac})_{2}$-soaked paper strips in $\mathrm{M} 9$ medium supplemented with $5 \mathrm{mg} / \mathrm{L} \mathrm{Na}_{2} \mathrm{SO}_{3}$. Values represented as means $\pm \mathrm{SD}(\mathrm{n}=3)$. $* * p<0.005$ was determined by one-way ANOVA and Tukey post-test.

A

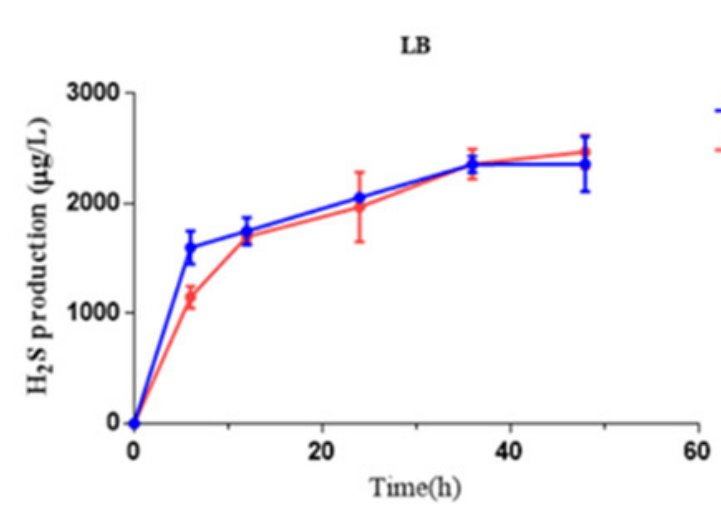

B

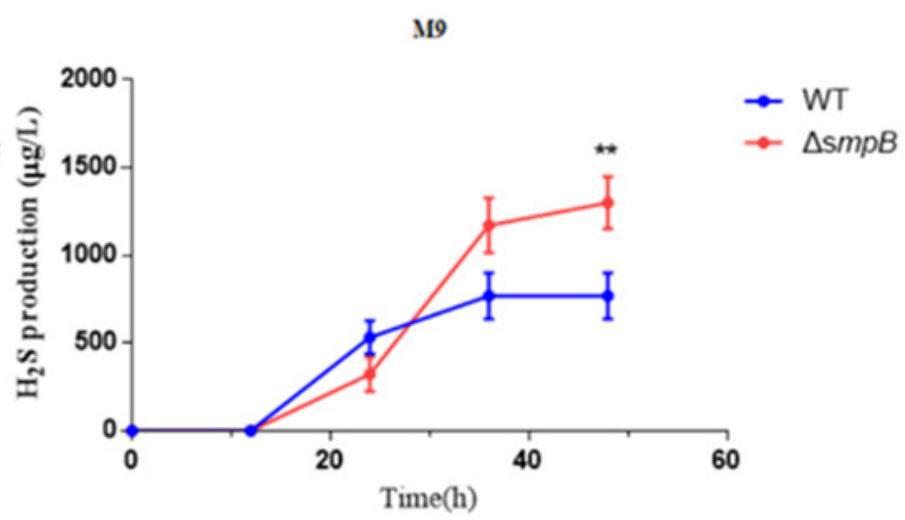




\section{Figure 3}

$\mathrm{Cbl}$ affected $\mathrm{H}_{2} \mathrm{~S}$ production by promoting the transcription of $\mathrm{cysH}$

(A) $\mathrm{H}_{2} \mathrm{~S}$ production was measured by $\mathrm{Pb}(\mathrm{AC})_{2}$-soaked paper strips in $\mathrm{M} 9$ medium supplemented with $5 \mathrm{mg} / \mathrm{L} \mathrm{Na} \mathrm{SO}_{3}$. The tested strains included WT, $\Delta c b /$ and the complemented strain $\left(\Delta c b /\right.$-Pcbl). Values represented as means $\pm S D(n=3) .{ }^{* *} p<0.005$ was determined by one-way ANOVA and Tukey post-test. (B) Fluorescence intensities were detected by Synergy $\mathrm{H} 1$ (BioTek) after the tested strains were treated with fluorescent $\mathrm{H}_{2} \mathrm{~S}$ probe in M9 medium. Values represented as means \pm SD $(n=3) .{ }^{*} p<0.01$ was determined by one-way ANOVA and Tukey post-test. (C) The relative expressions of $\mathrm{H}_{2} \mathrm{~S}$ synthesis genes were detected by qRT-PCR. Values represented as means \pm SD $(n=3)$. ${ }^{*} p<0.01$ was determined by one-way ANOVA and Tukey post-test. (D) Fluorescence intensities were detected by Synergy H1 (BioTek). The tested strains expressed PcyslJH only (pTRG+pUC19PcyslJH -eGFP), and co-expressed both Cbl and PcyslJH (pTRG-Cbl+pUC19- PcyslJH -eGFP), respectively. Values represented means $\pm S D(n=3) . * p<0.01$ was determined by one-way ANOVA and Tukey post-test. 
A

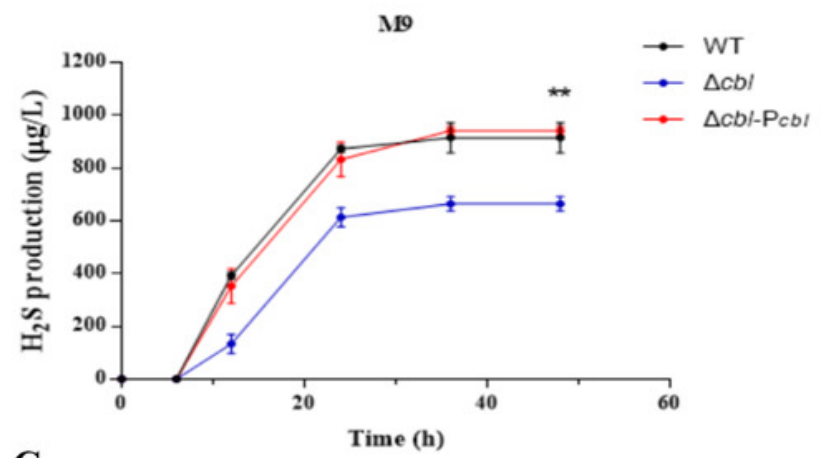

C

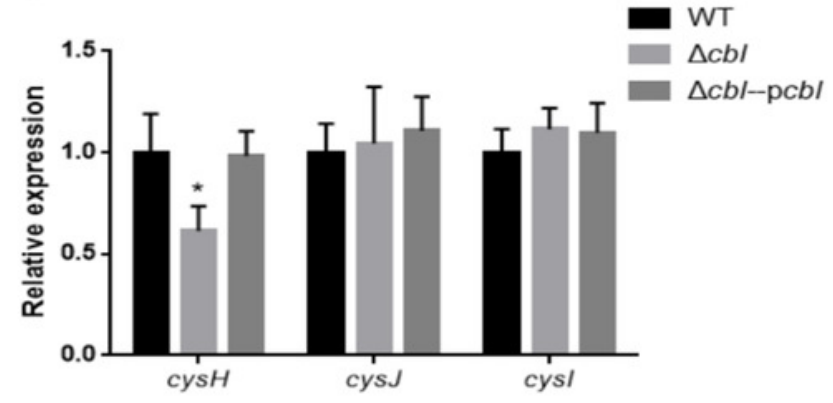

B

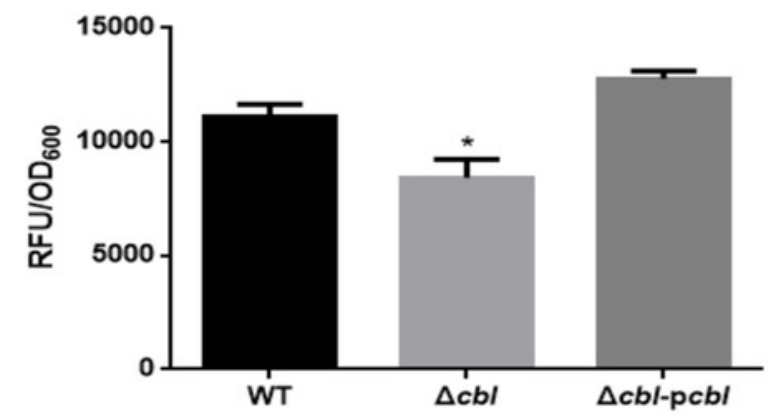

D

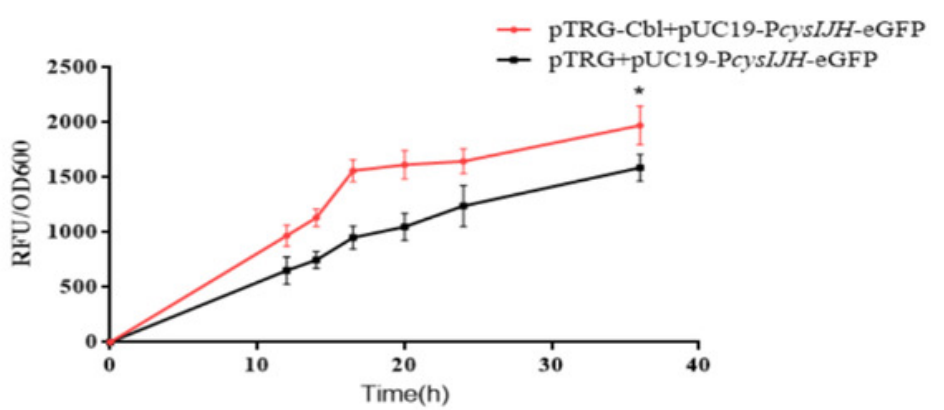




\section{Figure 4}

$\mathrm{Cbl}$ regulated downstream cysH by binding to the Pcys $/ \mathrm{IH}$.

(A) Results of bacterial one-hybrid. (B) Electrophoretic mobility shift assay (EMSA) for Cbl binding with Pcys $/ H$. The 25 nM FAM-labeled PcysJIH was incubated with the increased amounts of $\mathrm{Cb}$ protein. $\mathrm{Cb}$ protein was titrated to the concentration of $0 \mu \mathrm{M}, 10 \mu \mathrm{M}, 20 \mu \mathrm{M}$, $30 \mu \mathrm{M}, 40 \mu \mathrm{M}, 50 \mu \mathrm{M}$ and $60 \mu \mathrm{M}$. (C) Electrophoretic mobility shift assay (EMSA) for Cbl binding with the varied size of PcysJIH. PcysJIH contained 226 bp upstream of transcriptional initiation site, Pcys $J \mid H^{150}$ contained 150bp upstream of transcriptional initiation site, and Pcys $J H^{50}$ contained 50bp upstream of transcriptional initiation site. The $25 \mathrm{nM}$ FAM-labeled probe DNA was incubated with $60 \mu \mathrm{M} \mathrm{Cbl}$ protein. The experiments were repeated in triplicate. 
A

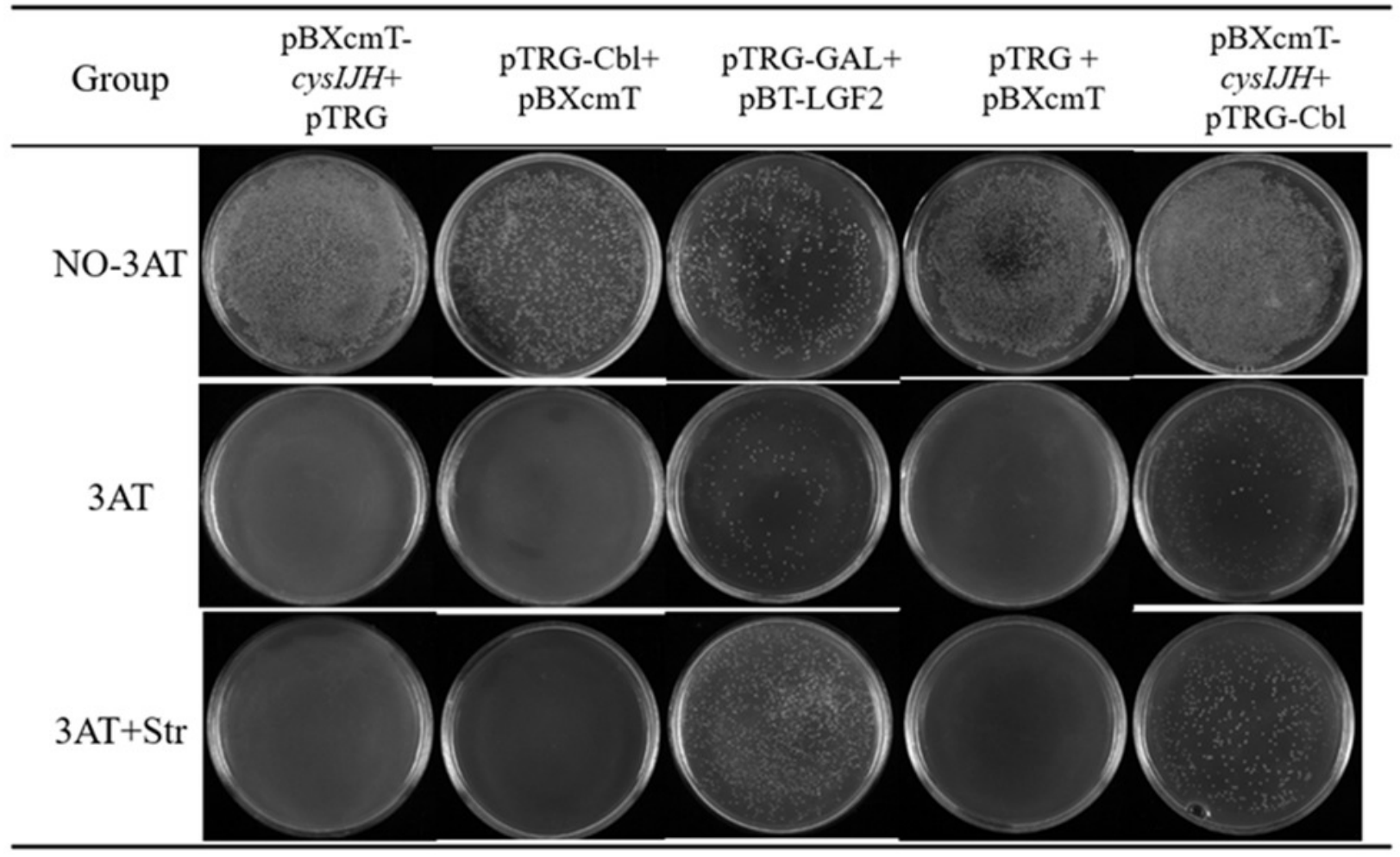

B

\begin{tabular}{|c|c|c|c|c|c|c|c|}
\hline $\mathrm{Cbl}$ & + & + & + & + & + & + & \\
\hline 6-FAM- $P_{c y s I J H}$ & + & + & + & + & + & + & + \\
\hline$P_{\text {cysIJH }}$ & - & - & - & - & - & - & - \\
\hline
\end{tabular}

C
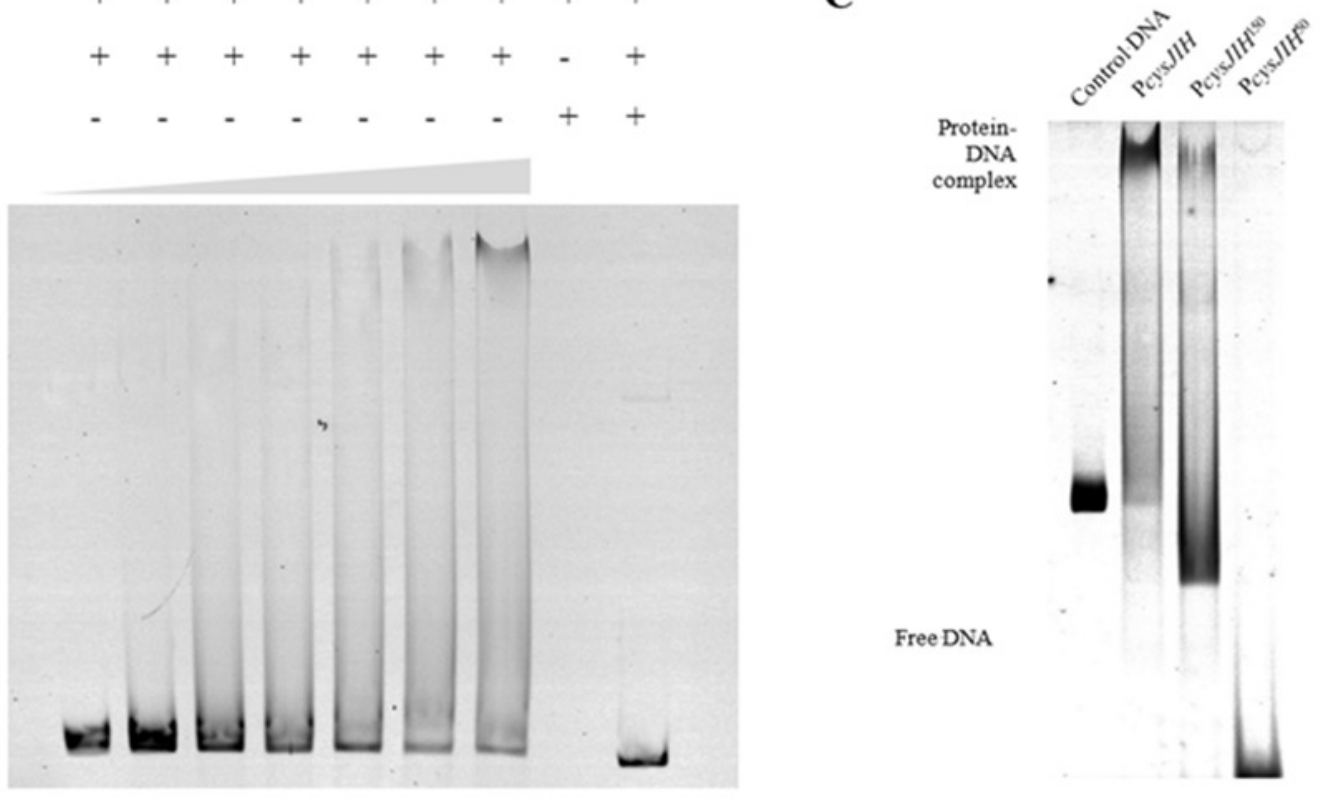

Free DNA 